\title{
WILEY
}

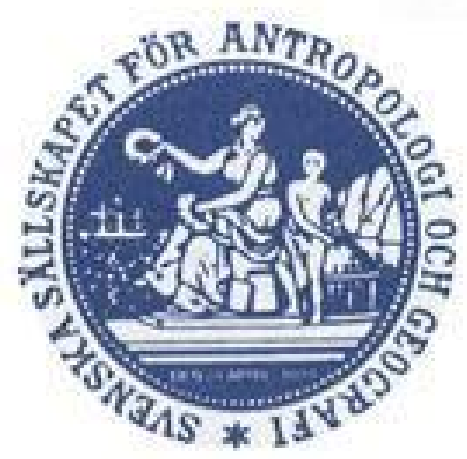

Meteorological Influences on the Level of the Sea-Surface Author(s): Hans Pettersson

Source: Geografiska Annaler, Vol. 3 (1921), pp. 165-182

Published by: Wiley on behalf of Swedish Society for Anthropology and Geography Stable URL: http://www.jstor.org/stable/519427

Accessed: 04-06-2016 21:02 UTC

Your use of the JSTOR archive indicates your acceptance of the Terms \& Conditions of Use, available at

http://about.jstor.org/terms

JSTOR is a not-for-profit service that helps scholars, researchers, and students discover, use, and build upon a wide range of content in a trusted digital archive. We use information technology and tools to increase productivity and facilitate new forms of scholarship. For more information about JSTOR, please contact support@jstor.org.

Wiley, Swedish Society for Anthropology and Geography are collaborating with JSTOR to digitize, preserve and extend access to Geografiska Annaler 


\section{METEOROLOGICAL INFLUENCES ON THE LEVEL OF THE SEA-SURFACE.}

BY HANS PETTERSSON.

I $\mathrm{n}$ an earlier communication to this journal $^{1} \mathrm{I}$ have set out the main results from an investigation of the relationship between meteorological influences and a special kind of oceanographical phenomena, viz. the large internal movements in stratified coastal waters, which movements were originally discovered and studied at our research station on Bornö in the Gullmar-tjord. The main results from this study were that the internal movements, as revealed by the vertical displacements of the boundary surface in the fjord, were in general strongly influenced by the wind, the velocity component about parallel to the main direction of the tjord (and nearly normal to the main coast-line) being on the whole the most effective in this respect. The air-pressure, on the other hand, was found to be practically void of any effects of this kind. A more quantitative comparison between the curves representing the daily average values of the wind-component and those giving the level of a certain isohaline in the fjord, as found from daily soundings, proved the two curves to be distinctly correlated, the coëfficients being for most of the months investigated of high numerical values. The investigation was extended also to wind-components of other directions and with variable differences of phase between the wind-curve and the isohaline-curve, the results proving that the maximum effect of the wind was attained after the lapse of between 24 and 48 hours. Cases when this wind-action was more or less obscured were found to be explicable from considerations of the state of stratification in the fjord, but it was expressly stated that influences other than meteorological might also affect the boundary, such as tidal forces of long period.

In the course of this study I found it desirable also to compare the variations in the level of the free surface in the fjord, as registered by a pneumatic maréograph at Bornö, with boundary surface variations. Drawing the surface-curve inverted and on a larger scale together with the other curves it was seen to be of a pronounced conformity with the wind- and the boundary-curves but to be also influenced by other factors (the air-pressure). The latter circumstance accounts for the failure I experienced when trying to obtain high correlation coëffi-

\footnotetext{
1 Geografiska Annaler I920 H. I, p. 33.
} 
cients between the surface- and the boundary-curves, one being affected by changes in the air-pressure and the other not. In general, however, the surface was found to become depressed and the boundary raised by a wind down the fjord and out from the coast, while a wind from the sea and up the fjord had the opposite effect. The two displacements were always on quite different scales of magnitude, the boundary surface rising and falling by 50 to Ioo times larger deflections than the free surface.

A quantitative study of the latter fluctuations was not comprised in the original plan for my investigation. The material required for this purpose was, however, obtained and partly worked up in the course of the main research and the subject in itself appeared of sufficient interest to be worth the extra trouble required for the necessary calculations, rather toilsome though they were.

A complete list of the factors capable of influencing the level of the free surface would include a number of forces of different origin, such as cosmic or tidal forces of different periods, aërostatic, aërokinetic, hydrostatic, hydrokinetic, seismic and electrostatic forces. Of these the two last are in general overlooked, their effects, although far from negligible, being on the whole too local or of too short duration to be taken into account in studies of a more general character. From a practical point of view the cosmic and the meteorologic factors are of special interest as they largely determine such changes in the sea-level which are of importance to navigation and for hydrotechnical works on the sea-coast. It is of course well known how the necessity for predicting the water-level in harbours with pronounced tidal fluctuations has given rise to that magnificent application of mathematical analysis to a practical problem which forms the base of the present system of tidal predictions. In their application to navigation these predictions, faultless in themselves though they are, become severely marred by the irregular interaction of meteorological influences, which superpose their effects on those of the tidal forces. These "meteorological tides", as they are somewhat illogically called, produce deviations between the water-levels predicted and those actually occurring, which deviations may sometimes have rather serious consequences. Quite a number of attempts have been made to bring the effects of the meteorological factors into the calculus, so as to make it possible to correct the predicted "cosmic" water-levels according to the prevailing atmospheric conditions, i. e. according to the wind and the air-pressure.

\section{Previous investigations of meteorological influences on the sea-level.}

In my previous paper on the meteorological influences on the internal movements in the sea I have very briefly indicated some of the earlier work done 
on the subject of the present paper ${ }^{1}$. A fact which it seems worth while to point out again also in this connection is that the discovery of the barometric effect on the sea-level, which is generally attributed to Aimé, was first published in Sweden by scientists of the 18 :th and the early 19 :th century. A considerable number of later studies of the same relationship are known from the scientific litterature of last century, most of them attempting to find the exact law giving the ratio between the changes in the sea-level and in the barometric pressure. The law for this relationship, found by the Swedish investigator Schultén in $1806^{2}$, viz. that the ratio is identical to that between the specific weights of mercury and of water, has been found to hold only as a rough approximation, the ratios found by different authors and even by the same author from different observations varying considerably and being in general distinctly lower than the above "statical" value, I3,6. Witting, the Finnish oceanographer, who has studied the surface-level records from a large number of stations round the Baltic seas and the North $\mathrm{Sea}^{3}$ has found the above ratio to be considerably lower, varying between 8 and 3 .

The effects of the wind on the water-level has also been the subject of numerous investigations. These effects are so obvious that they must have become known long before the barometric effects were recognised. No attempt towards a real analysis of this relationship seems to have been undertaken until the Danish physicist and engineer A. Colding published his classic investigations of the currents in the sea produced by the wind ${ }^{4}$ and applied the results thus obtained to a very complete study of the great flood which was raised round tbe Baltic and the North Sea coasts by a november gale in $1872^{5}$. References to this work by Colding and to some of the results gained by him will be made in the following.

Later on quite a number of investigators have dealt with related problems. The work by $\mathrm{R}$. Witting has already been mentioned. The object he had in view was to eliminate as far as possible the meteorological effects from the material investigated by him, so as to be able to find the actual displacements of the coast-line occurring at the present time. Like most recent workers on the same subject Witting considers mainly the joint effect of the wind and the airpressure on the sea-level and arrives to what he calls a "thalassological paradoxon",

\footnotetext{
${ }^{1}$ A more complete survey of the litterature dealing with this subject than can be given in the present paper may be found in a paper by Leverkinck to be quoted in the following.

2 K. Sv. Vetensk. akad. Handl. Stockholm 1806, P. 77.

${ }^{3}$ Fennia 39 N:o 5, Helsingfors 1918.

4 Vidensk. Selsk. Skr., 5 afd. XI 3, 1876 p. 249; Kbhvn.

5 Vidensk. Selsk. Skr., 6, I:ste Bd IV I88ı, p. 245 ; Kbhvn.
} 
viz. that the surface current raised by the wind runs obliquely up the slope of the sea-surface which is caused by the joint effects of the air-pressure and the wind.

Most investigations dealing with these subjects have, however, been undertaken with the object of making it possible to apply corrections to the ordinary tidal predictions, corrections for the disturbances due to the "meteorologic tides". Now all results so far gained seem to indicate, that these disturbances are distinctly local in character and vary considerably from one harbour to another. A seaward wind and a high pressure always tend to depress the water-level and vice versa, but the magnitude of the effect stands in no universally fixed proportion to the magnitude of the atmospheric disturbance which is its direct cause. It is therefore necessary to find out for each individual place what the local values for these ratios are and whether they are constant or not. This implies necessarily a comparison between prolonged series of observation of the local wind and air-pressure on one hand and the variations in the surface-level on the other. Investigations of this kind have been made by various authours, one of the more recent being a study by Leverkinck of the water-level in the German Bight and especially at Wilhelmshaven with regard to the influence of wind and air-pressure on the tides ${ }^{1}$. Some of the results found by Leverkinck will be discussed further on in this paper. Still more recently a similar study of the meteorological influences on abnormal high and low water-levels observed at some North German harbours has been published by C. Stellmacher ${ }^{2}$ who in general follows up the same lines of research as Leverkinck and makes use of the results obtained by this author.

Both the last named authors find it most expedient to regard the distribution of atmospheric pressure as the primary factor and attempt to bring in the wind as derived from it according to empirical rules for the relationship between the velocity and the direction of the wind and the barometric gradient. For practical purposes this may be so, provided the operator who has to find out the magnitude of the meteorological tide at a certain point can avail himself of the synoptic chart representing the actual meteorological situation. But from a theoretical point of view the coupling together of the wind and the air-pressure when trying to ascertain their joint effect on the water-level appears to be open to argument. Firstly the two factors act in fundamentally different ways on the water-level. Both of them, of course, tend to produce horisontal currents, but whereas the direct force exerted by the air-pressure is normal to the surface, the wind-force is tangential. The former force, therefore, being equivalent to

\footnotetext{
1 Veröff. d. K. Observ. in Wilhemshafen 1915.

2 Ann. der Hydrogr. 1920, Heft IX.
} 
an increase or to a reduction in the hydrostatic pressure tends to produce currents at all depths, whereas the immediate effect of the wind is limited to the surface sheet of the water, from which the motion produced can only spread gradually downwards by internal friction according to the well-known drift theory expounded by W. Ekman and others. Or, to put it more plainly, to the currents raised by a change in the atmospheric pressure the whole vertical section (normal to the barometric gradient) is open from the sea-surface to the bottom, whereas the wind-currents are from the first limited to a relatively thin surface layer of correspondingly small section. Consequently the linear displacements and the current velocities required to compensate for a change in the air-pressure are in general considerably smaller than those which a wind of corresponding strength tends to produce. The same applies of course to the kinetic energies of the two systems of currents. Hence one would expect the effects of the wind on the water-level to lag behind its cause by a much larger amount than the corresponding lag in the pressure-effect. Moreover the former lag should be relatively more dependant on the depth than the latter.

Secondly, when coordinating the wind with the barometric pressure in this respect one tacitly admits, that the effect of the wind on the water-level should vary as $w^{2}$, if $w$ is the velocity of the wind. For it is generally admitted that $w=C \sqrt{\Delta B}$ where $\Delta B$ is the barometric gradient. Now the tangential force exerted by the wind, i. e. the wind-pressure on a vertical surface normal to the wind-direction does in fact vary as $w^{2}$. But it does not appear self-evident that the effects of this force on the water-level, which are both direct and indirect in character, must necessarily also vary as the second power of the velocity. As will be seen from the following, there is a certain amount of evidence, both experimental and found by simple reasoning, that the wind-action is more likely to vary as $w^{k}$, where $k$ is lower than 2 but certainly higher than unity.

\section{Observations and method of calculation.}

The oceanographic observations on which this study is based are the records for the year IgII from a pneumatic maréograph, which registers the variations in the surface-level of the Gullmar-tjord (west coast of Sweden) at the oceanographic research station Bornö, situated about half-way up the fjord. An instrument of this type is particularly useful for studying the surface seiches and other variations of comparatively short duration. For longer series of measurement, where a high degree of accuracy or rather a perfect constancy of the zero is essential, say for geodetic purposes, the pneumatic maréograph is not so suitable, as its zero is liable to undergo slight variations with time. During 
the year here considered, the maréograph was kept in excellent condition, no breaks exceeding a few hours were experienced and the zero remained the same with a constancy quite sufficient for the present purpose.

The meteorological observations, which are the same as those used in my study of the internal movements, are the readings of the barometer and of the direction and the velocity of the wind (the latter by means of a cup-anemometer) taken from the lighthouse Hållö, situated some $20 \mathrm{~km}$. NW from the entrance to the fjord and some $40 \mathrm{~km}$. due west from Bornö. The readings are taken thrice a day, viz. at 8 a. m., at 2 p, m. and at 9 p. m. From each wind observation the component velocity along a certain direction was obtained

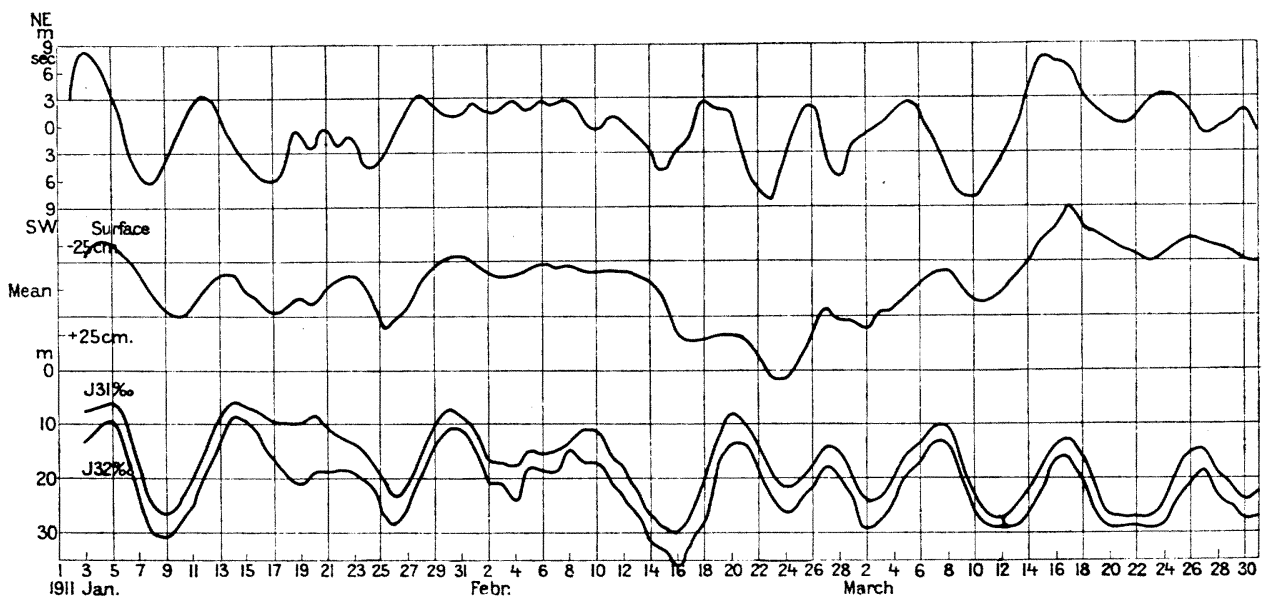

Fig. I

graphically, and daily average values for the component velocity were calculated, similar daily average values were also obtained for the barometric pressure.

In order to get comparable values from the surface records these were measured at the points which correspond to the time of the meteorologic observations. However, as a uninodal surface seiche of about 2 hours' period is a common occurrence in the fjord, each of the three points in the records was first corrected for the seiche-effect, if there was any visible in the record, by taking a mean value from $S_{7}, 2 S_{8}$ and $S_{9}$, and using instead of the uncorrected value $S_{8}$. The tides are not very prominent in the Gullmar-fjord. Still a maximum change from high to low water of some $30 \mathrm{~cm}$. at spring tide is observed. By taking the daily average from the three values of the surface-level just mentioned by the analogous method, viz. the arithmetic mean from $S_{8}^{\prime}, 2 S_{2}^{\prime}$ and $S_{9}^{\prime}$ the tidal effect is practically eliminated. 
Curves giving the daily average values thus found of the wind-velocity and the surface-level have been plotted and are to be found in my earlier paper together with isohaline curves showing the internal movements. I reproduce here in figure $I$ only the curves for the first quarter of 1911 , which show a distinct conformity between the three different kinds of curves. The surface curve is drawn inverted, high-water downwards and low-water upwards, and on a scale more than 30 times larger than the isohaline- (the boundary-) curves.

The method of quantitative comparison between the variations of the surfacelevel and those of the component wind-velocity and the air-pressure occurring simultaneously was the same I have applied to the study of the internal movements, viz. calculating the correlation coëfficients between these three variables. The series of daily averages were for that purpose divided into sections, one for each calendar month, monthly means were formed and the positive and negative deviations from these were taken for each individual value. These deviations were then treated in the well-known manner, which is also indicated in my paper already quoted. First the independant and then the partial coëfficients of correlation were calculated, the first according to the equation:

$$
r_{12}=\frac{\Sigma x_{1} x_{2}}{\sqrt{\Sigma x_{1}{ }^{2} \cdot \sqrt{ } \Sigma x_{2}{ }^{2}}}
$$

and the latter according to the equation:

$$
r_{12} \cdot 3=\frac{r_{12}-r_{13} \cdot r_{23}}{\left(\mathrm{I}-r_{13}\right)^{1 / 2} \cdot\left(\mathrm{I}-r_{23}{ }^{2}\right)^{1 / 2}}
$$

The indices I, 2 and 3 referring to the surface-level, the component velocity and the air-pressure in the order here given.

\section{Comparison of three days' average values.}

As I originally meant to carry out this investigation in complete conformity with my study of the internal movements, I first compared not the daily average values themselves but a smoothed-out series obtained by taking means from three consecutive days. The results from this calculation with the wind-component from the $\mathrm{SW} / \mathrm{NE}$ direction taken to be most effective ( $\mathrm{SW}$ positive and $\mathrm{NE}$ negative in sign) are set out in table I, where the first and the third columns give the independant, the second and the fourth columns the partial coëfficients of correlation.

The values of the partial surface-wind-coëfficients are seen to be positive 
without exception and mostly of "high" numerical values, if by high we denote a value more than six times larger than its probable error, a definition which for series of one month's length makes the numerical lower limit for "high" coëfficients fall a little over 0.5. According to a general convention the relationship is considered to be "proved", when the coëfficients exceed the limit just stated, and to be "probable" when this limit is not reached, but the numerical value is more than three times larger than the probable error, a limit which, again for monthly series, would correspond to coëfficients exceeding 0.35. According to this definition only the partial coëficients for the wind-effect in February and in September are seen to fall slightly below the limit for a probable relationship, whereas for the rest of the year, i. e. for ro of the months investigated, the relationship is seen to be "proved", the coëfficients being even in most cases very high. The average for $r_{12} \cdot_{3}$ from all the twelve months of the year is 0.609 , whereas if February and September are omitted the average from the other ten months comes out considerably higher still, viz. at 0.669 .

The partial coëfficients for the barometric surface effect are seen to be all negative and are in general numerically still higher than for the wind-effect.

\section{Table $I^{1}$}

\section{Three days' average values}

Wind SW/NE.

\begin{tabular}{|c|c|c|c|c|c|c|}
\hline & $r_{12}$ & $r_{12} \cdot 3$ & $r_{13}$ & $r_{13} \cdot 2$ & $b_{12} \cdot 3$ & $b_{13} \cdot 2$ \\
\hline Jan. & 0.595 & $0.62 \mathrm{I}$ & -0.676 & -0.695 & 2.253 & $-\mathrm{I} .628$ \\
\hline Febr. . & 0.628 & $0.33^{1}$ & $-0.98 \mathbf{I}$ & $-0.97 \mathrm{r}$ & 0.844 & -2.155 \\
\hline March & $0.65 \mathrm{x}$ & 0.564 & -0.693 & $-0.62 \mathrm{x}$ & 3.208 & -2.070 \\
\hline April . & 0.864 & 0.833 & -0.777 & -0.723 & 3.034 & -1.108 \\
\hline May & $0.57^{x}$ & 0.589 & -0.882 & -0.886 & I. 100 & $-1.43^{8}$ \\
\hline June & 0.664 & 0.794 & -0.600 & -0.759 & 1.564 & -0.889 \\
\hline July & 0.708 & 0.797 & -0.740 & -0.818 & 1.362 & -0.700 \\
\hline Aug. & 0.755 & 0.842 & -0.326 & -0.627 & 2.317 & -0.783 \\
\hline Sept. & 0.278 & 0.308 & -0.345 & $-0.3^{69}$ & I.015 & -1.013 \\
\hline Oct. & 0.359 & 0.550 & $-0.7^{13}$ & -0.779 & 3.032 & $-\mathbf{I} .75^{8}$ \\
\hline Nov. & 0.827 & $0.8 \mathrm{II}$ & -0.585 & -0.537 & 5.474 & -1.487 \\
\hline Dec. & 0.159 & 0.268 & -0.794 & -0.805 & I.orr & $-\mathrm{I} .507$ \\
\hline Average & +0.588 & +0.609 & -0.676 & -0.716 & +2.18 & $-\mathrm{I} .3^{8}$ \\
\hline
\end{tabular}

1 The units are in all the tables: $1 \mathrm{~cm}$. for the surface-level, I $\mathrm{m} / \mathrm{sec}$. for the wind, and $\mathrm{I} \mathrm{mm}$. (mercury) for the air-pressure. 
Only the month of September also in this case gives a low value for $r_{13} r_{2}$ whereas February shows instead an excessively high value, such as is rarely obtained in similar comparisons. The average value for the year is $r_{13} \cdot_{2}=$ -0.716 , which must be regarded as a very high value for an annual mean of this kind.

One may already at the present state of enquiry infer from these results, that both the wind-component from the $\mathrm{SW} / \mathrm{NE}$ direction and the air-pressure have an unmistakable influence on the surface-level in the Gullmar-fjord of the sign to expected from elementary considerations. Further, that this relationship is not always equally pronounced but varies considerably from month to month to the extent of becoming in exceptional cases nearly obscured. These variations do not run parallell for the two effects but seem to be quite independant of each other. Also the barometric effect is in general more pronounced than the windeffect.

Both the wind and the air-pressure being thus seen to exert a distinct influence on the water-level at Bornö, the "independant" coëfficients, $r_{12}$ and $r_{13}$ in table I have of course only a secondary interest. It is however worthy of observation, that the average value from each of these columns is distinctly lower than the corresponding average for the "partial" coëfficients.

The two last columns of the table contain the "partial" coëfficients of regression, which indicate the extent to which, according to this calculation, the surface-level has become displaced by a unit change in each of the two meteorological factors considered. The values of $b_{12} \cdot_{3}$ are seen to undergo very considerable variations from month to month, their minimum in February being 0.844 against a maximum value of 5.474 in November. The same months February, September and December which gave low values for the correlation are seen to come out badly also with regard to the regression coëfficients. Omitting these three months, the mean from the other nine is found to be 2.59 , whereas from all the twelve months one finds the annual mean to be 2.18. Bearing in mind the influence of the smoothing out process of forming three days' averages, this would imply, that a change in the velocity of the SW/NE component by I $\mathrm{m} / \mathrm{sec}$. would have raised or lowered the sea-surface at Bornö by an average amount of $2.18 \mathrm{~cm}$. for the whole year (or by $2.59 \mathrm{~cm}$. during the nine months with "proved" relationship).

The regression coëfficients for the air-pressure are seen also to vary from month to month but distinctly less than the wind-coëfficients. The variations do not appear to follow any distinct rule, except that the summer half of the year gives in general much lower values than does the winter. The average from all the twelve months is seen to be - r.s8, which means that a change in the barometer of $\mathrm{I} \mathrm{mm}$. produced a change in the surface of opposite sign and 
equal to $1.38 \mathrm{~cm}$. or $13.8 \mathrm{~mm}$. This ratio between the displacements of the mercury and the water is seen to be almost identical to the statical value $\mathrm{I}_{3.6}$ which was assumed to be self-evident by early writers on this subject.

\section{Comparison of the Daily average values.}

The smoothing-out process of taking three day's means employed in the preceeding part of this analysis was applied in conformity with my investigation of the internal movements. With these it had a real significance, since it was meant to eliminate the effects of internal seiches of a period between one and three days, such as have repeatedly been found to take place in the Gullmatfjord. A surface seiche of the same period appears unlikely to occur in these waters, as it would involve a standing wave-motion of quite improbable wavelength. For this reason it appears interesting to investigate also the series of daily average values obtained from the records without submitting them to any smoothing-out process. The calculations necessary for this purpose have also been carried out, the results appearing in tables II and III. In order to make the study more complete the same calculations have been gone through with all the four main directions of the wind-component, viz. SE/NW, $\mathrm{S} / \mathrm{N}, \mathrm{SW} / \mathrm{NE}$ and $\mathrm{W} / \mathrm{S}$. Besides, the two first giving between them the highest values for $r_{12} \cdot{ }_{3}$ a component of intermediate direction, viz. WSW/ENE has also been included. Only the "partial" coëfficients are given, the others being considered less important for reasons already stated.

The values of $r_{12} \cdot_{3}$ are seen to be always highest in one of the three last columns, the greatest number of maxima (in italics) occurring in the $\mathrm{W} / \mathrm{E}$ column. The average value from that column is also seen to be the highest but the WSW/ENE column comes very near it and the SW/NE column is not far behind, both the two first being "high" according to the usual convention. The variations from month to month are seen to be considerable, February and December having again low coëfficients whereas September is very low in the $\mathrm{SW} / \mathrm{NE}$ column but fairly high in the $\mathrm{W} / \mathrm{E}$.

The correlation coëficients for the air-pressure effect, $r_{13} \cdot_{2}$, are seen to come out much the same with all the five wind-components, as is also natural. The highest values are found with the WSW/ENE component but the two adjacent components give practically the same average values. These are in themselves high, falling well over the limit for "proved" relationship. The variations from month to month are conspicuous, but not quite as large as with the windcoëficients. The month September again gives a low value and so does August, whereas February, although quite high, is still seen to be considerably lower than with the smoothed-out series. 
Table II.

Daily average values.

\begin{tabular}{|c|c|c|c|c|c|c|c|c|c|c|}
\hline & \multicolumn{5}{|c|}{$r_{12} \cdot 3$} & \multicolumn{5}{|c|}{$r_{13 \cdot 2}$} \\
\hline & $\mathrm{SE} / \mathrm{NW}$ & $\mathrm{S} / \mathrm{N}$ & $\mathrm{SW} / \mathrm{NE}$ & WSW/ENE & $\mathrm{W} / \mathrm{E}$ & $\mathrm{SE} / \mathrm{NW}$ & $\mathrm{S}_{/} \mathrm{N}$ & $\mathrm{SW} / \mathrm{NE}$ & WSW/ENE & $\mathrm{W} / \mathrm{E}$ \\
\hline Jan.. & -0.212 & -0.193 & 0.526 & 0.642 & 0.653 & -0.715 & -0.700 & -0.749 & -0.764 & -0.727 \\
\hline Febr. ...... & -0.498 & -0.298 & 0.010 & 0.185 & 0.328 & -0.913 & -0.908 & -0.877 & $-0.87 x$ & -0.875 \\
\hline March & -0.417 & -0.106 & $06_{5} \mathrm{I}$ & $0.81_{3}$ & 0.861 & -0.742 & -0.693 & -0.71 & $-0.78 x$ & -0.835 \\
\hline April ... & -0.290 & +0.230 & 0.583 & 0.067 & 0.615 & $-0.77^{8}$ & -0.796 & -0.768 & -0.773 & -0.773 \\
\hline May & +0.035 & +0.335 & 0.516 & 0.496 & 0.450 & -0.823 & -0.807 & -0.829 & -0.843 & -0.849 \\
\hline June & -0.446 & +0.026 & 0.700 & $0.68_{4}$ & 0.677 & -0.564 & -0.517 & -0.626 & -0.604 & -0.670 \\
\hline July & -0.459 & +0.060 & 0.399 & $0.4 \times 9$ & 0423 & -0.688 & $-0.67 x$ & -0.657 & $-0.63^{2}$ & -0.679 \\
\hline Aug. & -0.372 & +0.307 & 0.682 & 0.643 & 0.637 & -0.225 & -0.362 & -0.443 & -0.397 & $-0.33^{8}$ \\
\hline Sept. & -0.450 & -0.164 & 0.222 & 0.408 & 0.535 & -0.373 & -0.307 & -0.356 & -0.407 & -0.427 \\
\hline Oct. & $-0.45^{8}$ & +0.142 & 0.564 & $9.62 \mathrm{x}$ & 0.678 & -0.798 & $|-0.787|$ & -0.834 & -0.827 & -0.824 \\
\hline Nov. ........ & -0.598 & +0.197 & 0.747 & 0.854 & 0.791 & -0.446 & -0.673 & $-0.6 \mathrm{x}$ & -0.600 & -0.474 \\
\hline Dec. & -0.197 & +0.175 & 0.279 & 0.307 & 0.303 & -0.700 & -0.739 & $-0_{75}$ & -0.744 & -0.725 \\
\hline Average: & -0.363 & +0.059 & +0.490 & $+0.56 \mathrm{r}$ & +0.579 & -0.647 & $|-0.658|$ & -0.685 & -0.687 & $\left|-0.68_{3}\right|$ \\
\hline
\end{tabular}

The regression coëfficients $b_{12} \cdot_{3}$ and $b_{13} \cdot_{2}$ are only given with the three components found to be most effective, vide table III. The wind coëfficients with the $\mathrm{W} / \mathrm{E}$ component are the highest and give an annual mean of - 1.85 against - I.6I with the $\mathrm{SW} / \mathrm{NE}$ component. The latter value is considerably lower than that found with the same component from the smoothed-out series a fact which is not without its significance. The variations from month to month are very large, the maximum being, as before, attained in November, although numerically much lower than with the smoothed-out data.

The regression coëfficients for the air-pressure are again seen to vary but little from one wind-component to the next. The variations from month to month are similar to those already met with. The average value for the year comes out highest with the $\mathrm{SW} / \mathrm{NE}$ component, viz. $b_{13} \cdot{ }_{2}=1.53$ which implies that the variations in the level of the sea and of the mercury should stand in the proportion $1: 15.3$ i. e. about $10 \%$ higher than the theoretical value and also higher than that found from table I. Thus, whereas the regression coëfficients for the wind-effect appear to be enhanced by the smoothing-out to three days' means, the same is not the case with the air-pressure effect, which appears instead, if anything, reduced by the same treatment. This difference between the two effects seems to be in agreement with the reasoning set out on page 169 
Daily average values.

Table III.

\begin{tabular}{|c|c|c|c|c|c|c|}
\hline \multirow[b]{3}{*}{ Jan.. } & \multicolumn{3}{|c|}{$b_{12} \cdot 3$} & \multicolumn{3}{|c|}{$b_{13} \cdot 2$} \\
\hline & $\mathrm{SW} / \mathrm{NE}$ & WSW/ENE & $\mathrm{W} / \mathrm{E}$ & $\mathrm{SW} / \mathrm{NE}$ & $|\mathrm{WSW} / \mathrm{ENE}|$ & $\mathrm{w} / \mathrm{E}$ \\
\hline & 1.570 & 1.678 & 1.653 & -1.897 & -1.806 & $-\mathrm{r} .639$ \\
\hline Febr. ......... & 0.035 & 0.646 & I.125 & -2.259 & -2.162 & -2.094 \\
\hline March & $2.78 \mathrm{x}$ & 3.190 & 3.252 & -2.017 & - I.9r3 & -2.003 \\
\hline April & I. .674 & I. .864 & I. 640 & $-\mathbf{I} .53^{\mathrm{I}}$ & $-\mathrm{I} .445$ & -1.509 \\
\hline May & 0.965 & 0.970 & 0.917 & - I. .569 & - 1.638 & -1.704 \\
\hline June & $\mathrm{I} .535$ & I. .302 & 1.307 & -0.939 & -0.906 & $-\mathrm{I} .09 \mathrm{r}$ \\
\hline July........... & 0.786 & 0.792 & 0.799 & -0.734 & -0.696 & $-0.75^{8}$ \\
\hline Aug. & I. 895 & I. 674 & 2.015 & $-0.74^{\circ}$ & -0.686 & -0.568 \\
\hline Sept. & 0.680 & 1.220 & I. .42 & -1.005 & -1.103 & $-\mathrm{I} .073$ \\
\hline Oct. & 2.424 & 2.543 & 2.919 & -2.289 & $-2.14 \mathrm{I}$ & -2.015 \\
\hline Nov. & 4.154 & 4.198 & 3.899 & -1.657 & $-\mathrm{I} .292$ & $-1 . \times 39$ \\
\hline Dec. & 0.956 & I.rr8 & I. 192 & -1.773 & -1.714 & $-1.6_{4} 6$ \\
\hline Average: & +1.62 & $+\mathrm{I} .77$ & +1.85 & $-\mathrm{I} .53$ & $-\mathrm{I} .46$ & -1.44 \\
\hline
\end{tabular}

of this paper. For if the effect of the wind is really separable from that of the air-pressure on account of the lag between the force and its effect being greater with the former force than with the latter, then the smoothing-out process, which gives more weight to relatively feebler winds of longer duration and constant direction than to short-lived and more violent squalls, must be expected to have the very effect on the coëfficients of regression which has been found above.

\section{On the proportionality between the velocity of the wind and its effect on the sea-level.}

I have hitherto only compared directly the velocity of the wind with the variations in the surface-level, that is I have assumed its effect to vary in the same proportion as the first power of the velocity $w$. Most authors who have written on the same subject are, however, of a different opinion on this point, holding that the effect of the wind on the sea-level must vary in the same proportion as the wind-pressure, i. e. as $w^{2}$ instead of as $w$. This assumption, which appears to be almost universally adopted, is originally founded on theoretical and empirical evidence brought forward by Colding in his classical investigations before mentioned. 
Starting from his study of the flow of water in pipes and channels Colding deduces a simple law for the effect of the wind on the surface-level, viz.

$$
w=C \sqrt{\frac{h}{l} \cdot H}
$$

or, after squaring

$$
h=\frac{\mathrm{I}}{C^{2}} \cdot \frac{l}{H} \cdot w^{2}
$$

where $w$ is the velocity of the wind blowing along a basin of the length $l$ and the depth $H, C$ is a constant and $h$ is the total difference in level of the surface due to the wind, which difference is equal to the sum of the deflections produced at the leeward and at the windward shore. The great mass of observations regarding the meteorological data and the change in the surface-level collected after the great flood of 1872 gave Colding an opportunity for testing the above equations. The results gave good agreement between observed and calculated levels, and since then Colding's law does not seem to have been seriously disputed.

Leverkinck's study of the effects of the wind on the tides in $\mathrm{W}$ ilhelmshaven has also been mentioned. 'In this very extensive study some 4,000 observations of high and low water have been used, the differences between the values ob. served and those calculated by tidal prediction have been computed and supposed to have been caused by meteorological influences. The author assumes a certain direction making the angle $K_{0}$ with the meridian to be "normal" i. e. that of the most effective wind-component. The deviation between observed and predicted water-level being denoted by $h$, and the velocity of the wind to which it is due denoted $w$, Leverkinck assumes the following equation to hold

$$
h=A \cdot w^{2} \sin \left(K_{0}+\beta+\Delta K\right)
$$

where $\beta$ is the angle between the wind and the meridian, $\Delta K$ is a small error in the direction supposed to be most effective and $A$ is a constant. Taking $\Delta K$ to be relatively small and expounding in series 16 equations are obtained, one for each of the chief directions of the compass. With these equations the observed deviations are then tested (after introducing certain corrections which may be passed over here). The author, finding all the constants to come out different for different velocities of the wind, divides the observations into different groups according to the strength of the wind observed. The results, viz. the values of the constants of the above equation as they come out for different wind-velocities are set out in a table ${ }^{1}$, from which I reprint the two first columns in table IV

1 Ibid. p. 23.

12. Geografiska Annaler 1921. 
of this paper. The first of these columns gives the wind-velocity in metres per second and the second the values of the proportionality factor $A$ in Leverkinck's equation. The variations in $A$ with increasing velocity of the wind are seen to be most conspicuous and to show a systematic decline in $A$ with rising velocity $w$. The rate of this decline is also seen to be remarkable. Remembering that the observations are likely to be particulary uncertain with the very lowest but also with the highest wind-velocities, the latter being also comparatively rare, we may omit the very first and also the few last of the values from a quantitative comparison. Comparing the value of $A$ at $w=2$ and at $w=\mathrm{I} 6$ we find that in the first case $A$ comes out nearly eight times higher than in the second, so that the products $A . w$ are nearly the same in value. I have given these products in the last column of table IV and with the omission of the extreme values of $w$ the quantity $A . w$ is seen to be nearly constant or at

Table IV.

\begin{tabular}{|r|c|c|c|c|c|}
\hline \multirow{2}{*}{$A$} & $A$ & $w . A$ & $w$ & $A$ & $w^{\prime} . A$ \\
\hline 0 & - & - & $\mathrm{II}$ & 0.58 & 6.38 \\
$\mathrm{I}$ & 4.20 & 4.20 & $\mathrm{I} 2$ & 0.54 & 6.48 \\
2 & 3.31 & 6.62 & $\mathrm{I} 3$ & 0.52 & 6.76 \\
3 & 2.40 & 7.20 & $\mathrm{I} 4$ & 0.48 & 6.72 \\
4 & 1.50 & 6.00 & $\mathrm{I} 5$ & 0.46 & 6.90 \\
5 & 1.08 & 5.40 & $\mathrm{I} 6$ & 0.44 & 7.04 \\
6 & 0.88 & 5.28 & $\mathrm{I} 7$ & 0.42 & 7.14 \\
7 & 0.75 & 5.25 & $\mathrm{I} 8$ & $0.4 \mathrm{I}$ & 7.38 \\
8 & 0.70 & 5.60 & $\mathrm{I} 9$ & 0.40 & 7.60 \\
9 & 0.66 & 5.94 & 20 & 0.39 & 7.80 \\
10 & 0.62 & 6.20 & - & - & -
\end{tabular}

least much less variable than $A$ itself. Bearing in mind that the other terms of the equation have also a certain effect on the results, we may infer from the table that a much less variable proportionality factor might have been obtained, if the velocity of the wind had entered the equation in the first power than in the second. Not having access to the vast material worked upon by Leverkinck I must so far limit myself to this suggestion.

It would, however, appear of a certain interest to try on the material used in my own investigation whether higher coëfficients of correlation are obtained by comparing the variations in the surface-level at Bornö with the component wind- 
pressure instead of with the component wind-velocity, i. e. to compare the daily average values of $w^{2} \cdot \sin \%$ with the surface- and the air-pressure values hitherto used, $\%$ being the angle between the wind and the "effective" direction. For this purpose each single value of the wind-velocity has to be squared and projected on the effective direction and daily averages from the products $w^{2} \cdot \sin \alpha$ thus obtained have to be calculated. Finally these are compared with the other two sets of values in the usual manner and coëfficients of correlation and of regression are computed. I have only gone through these rather lengthy calculations with one of the wind-components used in the preceeding study, viz. with the WSW/ENE component. The results, $r^{\prime \prime}$, are embodied in table $\mathrm{V}$ together with the analogous coëfficients obtained with the velocity in the first power $r^{\prime}$. The results are seen to be much the same in both cases, the annual average values being almost equal in magnitude. Thus also the wind-velocity squared gives in general high values for the correlation coëfficients although quite as variable as those found for the first power of $w$.

It seems to follow from this result that one should instead make use of daily average values of $w^{k} \cdot \sin \alpha$, where $k$ is less than 2 but larger than $\mathrm{I}$. The calculations necessary for a similar comparison, although quite simple, are rather toilsome, and I have hitherto only gone through them with one month of the year, viz. with January, taking the value of $k$ at $I_{1.5}$. The correlation coëfficient found in this manner was only slightly higher than those obtained with $k=\mathrm{I}$ and $k=2$.

Table $V$.

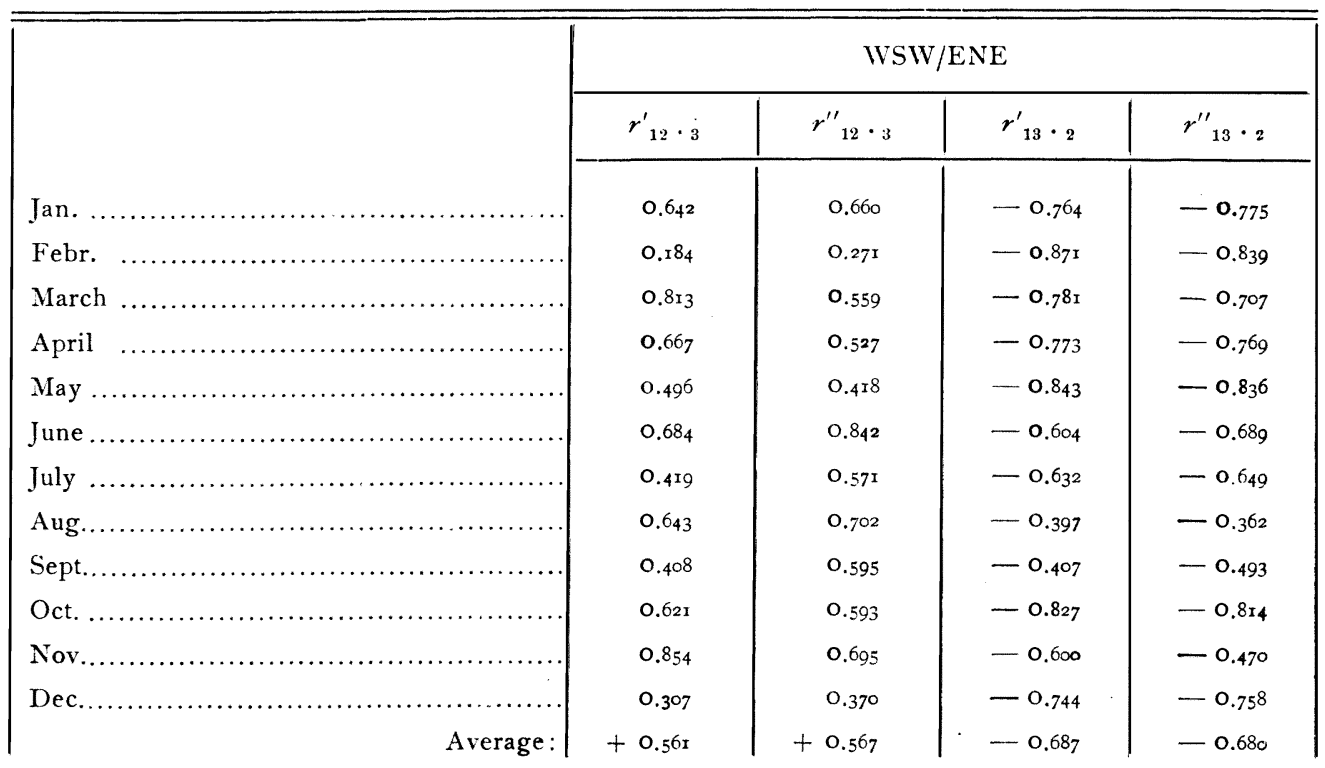


The correlation method as applied in this investigation is obviuosly not apt to give very sharp and definite results which might enable one to fix a certain value for $k$ giving the highest values for the correlation coëfficients. Probably $k$ would have to be varied from month to month in order to obtain the best results. But it appears probable that it would always have to be kept within the limits $\mathrm{r}<k<2$.

\section{Review of results and discussion.}

By the method used in this investigation it has beem ascertained, that both the wind and the air-pressure exert pronounced effects on the water-level in the Gullmar-fjord of the character to be expected. Thus a low pressure and a wind from the sea tend to raise the sea-surface above its average level, a wind from land and a high pressure having opposite effects. However, the correlation coëfficients proving this relationship, although always of the same sign, vary considerably in magnitude from month to month. The regression coëfficients which give a quantitative measure for the magnitude of each effect are also variable, but more so for the wind than for the air-pressure. The latter coëfficients moreover give average values for the whole year which come near the theoretical or "statical" ratio between the displacements of water and mercury surfaces 13.6 .

The method has been tried both with smoothed-out series of three days' means from the data observed and with daily average values, the former comparison giving on an average slightly higher values for the correlation coëfficients and distinctly higher values for the regression coëfficients relating to the wind, while those for the air pressure are much the same in both cases. A comparison has also been carried out with wind-components of different directions, those falling between $\mathrm{SW} / \mathrm{NE}$ and $\mathrm{W} / \mathrm{E}$ being decidedly most effective.

Finally a similar comparison has also been made with the WSW/ENE direction, on which the squared wind-velocities have been projected. The correlation coëfficients then obtained were on an average about as high as those found with the simple wind-velocities. A preliminary attempt with the wind-velocity raised to 1.5 gave only slightly better results. The inference drawn from this fact, viz. that the effect of the wind on the surface-level cannot, as is generally assumed, be strictly proportionate to the second power of the wind-velocity, i. e. to the wind-pressure, was found to be confirmed by the results found in the harbour of Wilhelmshaven by Leverkinck.

The discussion of my own results may be made very brief. The attempt made in this investigation to separate the effects of the wind on the surfacelevel from those of the air-pressure, has in the main been successful, the results 
proving- that both effects vary considerably from month to month but independantly of each other, so that the wind-effect may appear very feeble during a month with a very high air-pressure effect. This in itself seems to afford a sufficiently strong reason for not coupling both effects together, as is generally done by present investigators. Moreover a similar coordination is only justifiable if both effects follow the same law of variation, i. e. if the wind-effect is proportionate to the second power of the vind-velocity, since that power itself is proportionate to the air-pressure, or rather to the barometric gradient. According to the last of the results mentioned above this supposition fails, the wind effect apparently following a power of the velocity which is lower than 2 .

The results of this study thus throw doubts on the general validity of Colding's law. An elementary reasoning leads to the same result. The effect of the wind on the surface-level cannot only be due to the direct effect of the windpressure on the sea-surface. Part of it must be due to the hydrokinetic forces of the currents which are gradually set in motion by the same pressure. The rise of the surface at Bornö produced by a strong wind from the sea does not subside at once if the wind suddenly abates or changes its direction by $90^{\circ}$. The ingoing surface current will go on running inwards with considerable strength for quite a long time afterwards, and the water will only gradually get back to its normal level as this current subsides. Consequently the deflection of the surface due to the wind $\Delta h_{v v}$ must be composed of two terms $\Delta h_{v w}=$ $=\Delta h_{p}+\Delta h_{k}$, one $\Delta h_{p}$ representing the immediate effect of the wind-pressure and the other $\Delta h_{k}$ the effect of the hydrokinetic forces inherent in the currents raised by the wind. The first term may be assumed to vary as the second (possibly even as a slightly higher) power of the velocity, whereas the second term may be expected to vary at a slower rate and to be moreover dependant on the length of time during which the wind-pressure has been acting on the currents. Only the first term may therefore be grouped together with the airpressure effect, and their joint action on the surface studied, but the second term should be treated separately. The relative magnitude of these two terms cannot at present be ascertained. It may however be of interest to remark here, that the author in his paper on the internal movements already quoted has found, by a necessarily very rough calculation, that the energy inherent in the currents raised in the Gullmar-fiord by a gale is considerably larger than the potential energy corresponding to the deflections of the free and the boundary surfaces.

This problem, which involves the distribution of velocities and pressure caused by wind and air-pressure in the Gullmar-fjord, is unfortunately not open to exact treatment owing to the unknown influence of the friction in the water. The stratified state of the water, a complication which has not at all been dealt with in this 
study, tends to make the mathematical difficulties still more formidable. The author hopes, however, to get more detailed empirical data regarding the action of wind and air-pressure on the currents and the surface-level in our fjords, especially the Gullmar-tjord and the fjords leading into the harbour of Gothenburg. In order to get a clearer conception of the relationship between the wind and the air-pressure on one hand and the surface level on the other, especially with regard to the differences in phase or the "lag" between each force and the effect it produces, it will be necessary to get continuous records for all the three variables in question. This involves the use of a recording anemometer or an equivalent instrument, which the author hopes to secure for the measurements to be undertaken next summer. By means of a similar instrument combined with the apparatus established at Bornö for recording the movements of the boundary, the relationship between the deflections of the surface-level, the internal movements in the fjords and the meteorological factors here considered may be submitted to a more searching investigation.

\section{SUMMARY.}

I. The changes of the surface-level in the Gullmar-fjord during I9I I have been studied in their relationship to the local wind and the air-pressure by the correlation method. The separate effects of both forces are manifest during the whole of the year but to an extent which varies considerably from month to month.

2. The average ratio between the barometric variations and their effect on the surface-level comes near the theoretical ("statical") value I : I3.6.

3. A separate comparison between the surface changes and the wind-pressure instead of the wind-velocity seems to indicate, that the wind-effect is not strictly proportionate to the second power of the velocity ("Colding's law") but to a lower power, which falls between I and 2. An elementary explanation for this fact is propounded.

4. The method ordinarily employed of linking the wind and the air-pressure together when studying their effects on the surface-level is criticised.

5. Lines for further research on the same subject are indicated.

Oceanografiska Institutionen vid Göteborgs Högskola, Februari r92I. 